Vol. 2, "Aerostructures", is much more clearly defined in its presentation, and gives the impression that here the author is more at home with his subject. Again his choice of examples might have been more up to date. His figures for the comparison between a biplane and a monoplane are based on practice of several years ago. There is an excellent chapter on weight distribution and its estimation, a subject which has seldom been treated properly or as fully in other published text-books. Load factors are also dealt with fully, another subject none too clearly treated in other books. Mention should have been made of the possibility of these being varied as our knowledge of the principles of aerodynamics is extended.
When the author reaches the really practical aspects of design in chapters such as wing design, under-carriages, and metal construction, he becomes very sketchy in his treatment. It is, of course, impossible to treat such subjects in any other fashion in so small a compass, and it might have been better to have covered a smaller field more thoroughly. For example, a chapter on testing scarcely comes within the province of "Aircraft Design". The subject-matter in these chapters is accurate and useful so far as it goes. One is tempted to hope that the author will find it possible to extend future editions, and give his readers the benefit of the detailed knowledge of this part of the subject that he obviously possesses.

\title{
PROGRESS IN BIOCHEMISTRY
}

Annual Review of Biochemistry

James Murray Luck, Editor; James H. C. Smith, Associate Editor. Vol. 8. Pp. ix +676. (Stanford University P.O., Calif: Annual Reviews, Inc., 1939.) 5 dollars.

THE editors emphasize the need for critically appraising contributions of major significance rather than attempting a mere catalogue of papers, so that presumably this year's reviews, of which there are twenty-five, have been written from this point of view. Even so, they are mostly so highly specialized as to be too difficult for anyone but the experts.

Under the heading biological oxidations, Mr. Dixon notes the discovery of a new coenzymenucleotide and of new catalytic flavoproteins. In point of fact, rapid progress is being made in this group, but it requires a year or two yet before the results can be pulled together and a clear story made out of them.

The enzymes are dealt with in two sections, proteolytic and nonproteolytic. The work is now mainly chemical and slow progress is being made. K. Myrbäck devotes a few pages to the discussion of the various amylases: it is now admitted that they belong to clearly different groups producing from starch either alpha maltose or beta maltose or stable dextrins which vary in nature. It is inferred that the starch molecule cannot be so simple as deduced from the formula of Haworth. What a difficult problem starch presents! It has perhaps the largest literature of any compound and is one of the commonest of substances.

Karl Freudenberg selects lignin for discussion among polysaccharides and has put forward what seems to him the most logical conception of spruce lignin structure. The fundamental type unit, a skeleton containing nine carbon atoms, is a substituted phenyl propane, and it is considered that lignin is composed of a number of similar units connected through an ether linkage between phenolhydroxyl and the carbinol group of the side chain. The origin of lignin in the plant can only' be conjectured. It may come from pectin, but it is more probably derived directly from hexoses. The relation of lignin to the many phenolic glycosides also requires consideration. $\mathrm{X}$-ray studies are doing so much to advance the knowledge of the structure of compounds of biological interest that it is valuable to have a note on this subject from W. T. Astbury.

Chapters follow on fats, proteins, and sulphur compounds and on several branches of metabolism.

There is more work on hormones than ever, particularly in the steroid group relating to sex and adrenocortical hormones. John Freud and two other Dutch workers contribute a very useful summary in which they cite 550 papers and books. The vitamins are distinguished as water-soluble and fat-soluble. There is an interesting note by C. H. Best and J. H. Ridout of Toronto on choline, which acts in the diet to inhibit the accumulation of neutral fat and cholesterol esters in, and accelerates their disappearance from, the liver.

Reference has only been made to half the reviews; it must suffice to show how much work is going on and how valuable these reports are. Messrs. Murray Luck and James Smith have once more earned the thanks of their biochemical colleagues. 